\title{
MOTOR CONTROL
}




\section{MOTOR CONTROL}

Edited by

G. N. Gantchev

B. Dimitrov

and

\section{P. Gatev}

Institute of Physiology

Bulgarian Academy of Sciences

Sofia, Bulgaria 
Library of Congress Cataloging in Publication Data

International Symposium on Motor Control (5th: 1985: Varna, Bulgaria) Motor control.

"Proceedings of the Fifth International Symposium on Motor Control, held June 10-15, 1985, in Varna, Bulgaria"-T.p. verso.

Includes bibliographies and index.

1. Neuromuscular transmission-Congresses. 2. Sensory-motor integrationCongresses. 3. Afferent pathways-Congresses. 4. Locomotion-RegulationCongresses. I. Gantchev, G. N. II. Dimitrov, B. III. Gatev, P. IV. Title. [DNLM: 1. Motor Activity-congresses. 2. Movement-congresses. 3. Nervous Systemphysiology-congresses. 4. Posture-congresses. W3 IN91985 5th 1985m / WE 103 I601 1985m]

QP369.5.158 1985

$599^{\prime} .01852$

$87-2326$

ISBN 978-1-4615-7510-8

DOI 10.1007/978-1-4615-7508-5

Proceedings of the Fifth International Symposium on Motor Control, held June 10-15, 1985, in Varna, Bulgaria

(c) 1987 Plenum Press, New York

Softcover reprint of the hardcover 1st edition 1987

A Division of Plenum Publishing Corporation 233 Spring Street, New York, N.Y. 10013

All rights reserved

No part of this book may be reproduced, stored in a retrieval system, or transmitted in any form or by any means, electronic, mechanical, photocopying, microfilming, recording, or otherwise, without written permission from the Publisher 
This book encompasses part of the papers presented at the Fifth International Symposium on Motor Control held in Varna, Bulgaria from 10 to 14 June 1985. The Motor Control Symposia organized in Bulgaria became tradition following the successful initiation of Professor Gydikov and his collaborators of the previous four meetings (Sofia, 1969, Varna, 1972, Albena, 1976, Varna, 1981). More than 140 scientists participated in the last Symposium, 40 from East Europe, 15 from West Europe, 15 from USA and Canada. These Symposia established an opportunity for encounter of prominent scientists from all over the world, representatives of different schools and mainstreams. The participation of R. Granit, W. R. Ashby, B. C. Matthews, V. S. Gurfinke1, E. V. Evarts etc., is to be mentioned.

The main topics of the Symposium included: 1) Motor Unit Activity; 2) Reflex Control of Movements; 3) Central Control of Movements; 4) Posture Control; 5) Locomotion; 6) Arm Movement; 7) Motor Control Mode1s. 43 ora1 presentations and 103 posters were reported, 36 of them being presented in this volume.

The presented papers deal with the complex mechanisms of movement and posture control, investigations of considerable interest in recent years. This interest was prompted by the huge biological importance of the motor activity as a most common mechanism of adaptation to the environment. Motor activity is also inadvertently involved in various fields of human practice: occupational activities, including extreme conditions, motor handicaps, sports, bioprosthetic devices, bionics, robotics etc.

The problem of central mechanisms of movement and postural regulation was enlightened by new data concerning the role of various brain structures and certain psychophysiological processes in the organization of the motor activity. Some neurophysiological data concern, more or less directly, the question of voluntary control of movements and posture - a problem that occupies central position in the motor control versatility. The invited lecture of Dr Edward Evarts, unfortunately no longer with us, was dedicated to the problem of the neurophysiological mechanisms of the central control of movements. An obituary, prepared with the collaboration of Jerome Sanes from NINCDS at NIH, Bethesda, appears in this book with our deepest reverence to that eminent man and scientist. Dr Evarts was a great friend of the physiologists from Eastern Europe and, especially, Bulgaria. Dr G. N. Gantchev, Head of the Department of Motor Control at the Institute of Physiology, Bulgarian Academy of Sciences worked for some time in the Laboratory of Neurophysiology in Bethesda. Dr Evarts visited the Institute of Physiology in Bulgaria in 1980 and was a guest of honor at the

Symposium. He also was delegated the mission of further extending collaboration in the field of neuroscience between National Academy of Sciences in USA and Bulgarian Academy of Sciences. 
The problem of sensory control of movements posture and locomotion stands in relevant position. The role of different sensory inputs for the reflex and central regulation of movements and posture, their relationship and integration at different functional levels was discussed.

New data were presented regarding the peripheral control of movements and posture; activity of alpha-motoneurones and Motor Unit Activity in phasic movements and gait with different patterns of muscular activity; and the functional differentiation of MUs.

Parallel to the studies of different links in the system for control of movements and posture, investigations involving certain mechanisms at system level emerged. They comprise the investigation of some biomechanical features of voluntary movements and locomotion. This approach to the study of motor activity nowadays acquired immense importance due to the fact that data about biomechanical investigation at the system output level and about neurophysiological action of its separate levels are being synthesized. Some of the studies dealing with models of motor regulation presented examples of this multifarious state of the art.

A characteristic feature in the recent exploration of motor activity is the ever increasing number of human studies. It is demonstrated in two thirds of the works presented in this book. This scientific venue has the obvious advantage of prompt prospects for application into practice. Some papers were devoted to the clinical neurophysiology studying mechanisms of regulation in motor disturbances: a fruitful approach assisting the treatment of neurological patients.

The multitude of the presented papers assessing different neurophysiological, psychophysiological and biomechanical aspects of the motor control in normal and pathological conditions creates opportunity for estimation of the data in their complex interrelationships in the regulation system as a whole, for synthesis of the various fragments, for begetting of new ideas and widening of the current knowledge. This standpoint was proved also during the discussions at the Symposium and we do hope that the reader will appreciate the book from this viewpoint as well.

Unfortunately, a considerable amount of papers related to important problems of motor control did not find place in this book hindered by either volume restrictions or presentation elsewhere.

Our thanks are going to Plenum Publishing Corporation Ltd., for their valuable help and encouragement while preparing this book, an extension of our collaboration since the first Motor Control volume from 1973, comprising papers presented at the Second Symposium of Motor Control. We thank too all contributors and participants in the Symposium as well.

\section{G. N. Gantchev} Editor 
CONTENTS

Edward Vaughn Evarts

$\mathrm{xi}$

SECTION I. MOTOR UNIT ACTIVITY

The Pattern-Related Modifications of Contractile Response of Human Skeletal Muscle

V. S. Gurfinkel and Yu. S. Levik

Motor Unit Discharges in Interosseus Dorsalis Primus Muscle during Voluntary Movements

D. Kosarov, A. Gydikov, and A. Kossev

The Use of Low and High Threshold Units during Voluntary Contraction and Locomotion

L. Grimby

Measurement and Characteristics of Recurrent IPSPs Produced by Stimulation of Single Motor Axons

T. M. Hamm, C.-S. Yuan, S.-I. Sasaki, and D. G. Stuart

Application of Cross-Sectional Single-Fiber Microchemistry to the Study of Motor-Unit Fatigability

P. M. Nemeth, T. M. Hamm, D. A. Gordon, R. M. Reinking, and D. G. Stuart

SECTION II. REFLEX CONTROL OF MOVEMENTS

Development of Cutaneous Reflexes in the Upper Limb during Man Ontogenesis

V. Gatev, M. Stefanova-Uzunova, and L. Stamatova

M2-A Long Latency Spinal Reflex Due to Skin Afferents in Man

M. Shahani, 0. C. J. Lippold, K. Darton, and U. Shahani

Factors which Modify the Short and Long Latency Components of the Stretch Reflex in the Human Forearm

R. G. Lee, R. Hayashi, and W. Becker

Changes in Stretch Responses due to Hypotonia

A. Struppler, H. Riescher, and L. Gerilovsky 
Presynaptic Inhibition and Disinhibition of Monosynaptic

Reflex in Man

R. Person and G. Kozhina

The Differentiation of Golgi Tendon Organs in the Rat Hind Limb Muscles after Neonatal De-efferentation

T. Soukup and J. Zelená

SECTION III. CENTRAL CONTROL OF MOVEMENTS

Trigeminal Afferents to the Fastigial n. and Paleocerebellar Modulation of Hypoglossal Motoneurons: Neuroanatomical and Electrophysiological Study Suggesting a Transcerebellar Loop for Tongue Muscle Activity Regulation

A. Bava, F. Fabbro, S. Minine1-Conte, G. Leanza, A. Russo, and S. Stanzani

EMG and Hippocampa1 EEG Activities during Spontaneous and Elicited Movements in the Rat

R. Korczytiski, S. Kasicki, and U. Borecka

Higher Disturbances of Movement in Monkeys (macaca fascicularis) U. Halsband

Characteristics of Dentate Neuronal Discharge in a Simple and a Choice Reaction Time Task in the Monkey

C. E. Chapman and Y. Lamarre

Movement Related Brain Potentials in Sustained Isometric Voluntary Contraction

B. Dimitrov, G. N. Gantchev, and D. Popivanov

Are Self-Paced Repetitive Fatiguing Hand Contractions Accompanied by Changes in Movement-Related Brain Potentials?

G. Freude, P. U11sperger, and M. Pietschmann

Effects of Antagonist Activation on Sensations of Muscle Force L. Jones and I. Hunter

Initiation of Electromyographic Activity in Fast Forward Arm Elevation

P. Gatev, G. N. Gantchev, R. Koedjikova, and B. Dimitrov

SECTION IV. POSTURE CONTROL

Bulbar Reticular Unit Activity Relating to Posture and Skilled Forelimb Movement in Rats

M. Šaling, J. Kundrát, and P. Duda

Putative Neurophysiological and Neurochemical Mechanisms Underlying Striatal Control of Postural Adjustment in Dogs

K. B. Shapovalova and I. V. Yakunin

Role of the Visual Feedback for Stabilization of Vertical Human Posture during Induced Body Oscillations

G. N. Gantchev, P. Gatev, N. Tankov, N. Draganova, S. Dunev and D. Popivanov

Afferent Control of Posture and Gait

J. Quintern, W. Berger, and V. Dietz 
Facilitation of Vestibulo-Motor Response by Voluntary Movements in Man

B. N. Smetanin, V. Ju. Shlikov, and M. P. Kudinova

Evaluation of Mechanisms of Postural Regulation by Means of Time Series Analysis

D. Bräuer and H. Seide1

The Effect of Support Unloading on Characteristics of Motor Control Systems Activity

I. B. Kozlovskaya, I. F. Aslanova, and A. V. Kirenskaya

\section{SECTION V. LOCOMOTION}

Activity of Ventral Spinocerebellar Tract Neurons Chronically Recorded in the Spinal Cord of Awake, Freely Moving Cats

C. L. Cleland and J. A. Hoffer

Activity Patterns of Identified Alpha Motoneurons to Cat Anterior Thigh Muscles during Normal Walking and Flexor Reflexes

G. E. Loeb, J. A. Hoffer, N. Sugano, W. B. Marks,

M. J. O'Donovan, and G. A. Pratt

Antidromic Discharges of Primary Afferents during Locomotion

R. Dubuc, J.-M. Cabelguen, and S. Rossignol

Responses of the Forelimb to Perturbations Applied during the Swing Phase of the Step Cycle

T. Drew and S. Rossignol

Comparative Analysis of the Kinematical Characteristics of Man's Walking in the Ontogeny

E. N. Artemjeva and V. V. Smolyaninov

SECTION VI. MOTOR CONTROL MODELS

A Model for One-Joint Motor Control in Man

R. M. Abdusamatov, S. V. Adamovich, and A. G. Feldman

System Identification in Motor Control: Time-Varying Techniques

I. Hunter and R. Kearney

Workspace Effect in Arm Movement Kinematics Derived by Joint Interpolation

J. M. Hollerbach, S. P. Moore, and C. G. Atkeson

Kinematic Form of Limb and Speech Movements

D. J. Ostry, J. D. Cooke, and K. G. Munha11

Synergetics at Motoneuron Leve1

St. Baykushev

Index 
EDWARD VAUGHN EVARTS

Bethesda, Maryland

12 November 1985

Edward Vaughn Evarts died on the morning of 2 July 1985 from a heart attack at the age of 59 . He had just returned to Bethesda earlier than planned, and seemingly healthy, from a trip to Eastern Europe and to Finland; the native country of his wife Ritva. On this trip, the last of many to Eastern Europe, Ed participated in an international symposium on Motor Control; this book represents the record of that meeting. Although the content of his address to the meeting was on brain neuronal activity and movement, discussions at the symposium further stimulated Ed's interest in human motor control. Forthwith he conceived a series of experiments to study the relationships between voluntary movement and cerebral events in humans. These studies, due to begin soon after the arrival to the Laboratory of Neurophysiology of a colleague from Bulgaria, were a major topic of conversation in the laboratory on the morning of Ed's death and a reason for his early return. Although this work represented a departure for Ed from previous research methods and questions, it demonstrated a willingness to pursue new ideas and inject new techniques into his search to understand brain function.

In between medical training at Harvard University and a medical residency at the Payne Whitney Clinic in New York and a neurology fellowship at the National Hospital for Nervous Diseases in London, Ed began his research career at the Yerkes Primate Research Center, then located in Orange Park, Florida, under the direction of Karl Lashley. Ed's studies at Yerkes were concerned with the behavioral effects of ablation of auditory and nonprimary visual cortex in monkeys. Perhaps it was Lashley's influence that imbued Ed with the often stated goal of investigating questions relating to whole brain function and not simply with questions designed to provide small increments in knowledge about how the brain worked.

In 1953, Ed began a 32 year association with the National Institute of Mental Health that culminated in 1970 with his position as Chief of the Laboratory of Neurophysiology. At first Ed studied the effects of psychoactive drugs on the brain, but soon devoted his attention to understanding brain physiology by recording responses in the primary visual pathways to electrical and photic stimulation. Later on he investigated spontaneous activity in the visual cortex during sleep and waking. These studies led directly to those on the motor cortex of the monkey for which Ed's contribution to neurobiology are best known. He is generally credited with making the critical developments in the method of chronic single unit recording, first originated by Jasper and Hubel, so that the method became a practical means of neurophysiological investigation. That countless neurophysiologists now employ this method to evaluate the activity of 
neurons in awake animals is testament enough to Ed's contribution to neurobiology. However, Ed was not satisfied merely with technological innovation. His seminal studies on the discharge properties of physiologically identified neurons in the motor cortex of monkeys that performed voluntary movements stand as important contributions not only to motor control research but also to integrative neurophysiologists as paradigms. Ed's interests extended to many aspects of neurobiology; a reflection of that was direct participation in studies of human motor control in both normal subjects and those with neurological disorders and support of research within the Laboratory of Neurophysiology into the physiological, anatomical and chemical organization of the cerebral cortex, basal ganglia, thalamus and cerebellum. A11 of these interests were well integrated as exemplified by coordinated studies which evaluated the detalls of human movements or neural responses in the motor cortex of monkeys in similar behavioral tasks.

In addition to maintaining an active research and training program which has produced several prominent neurobiologists, Ed contributed to the worldwide development of neuroscience. A litany of his contributions could not do justice to their collective impact but a few are nevertheless remarkable. His trips to Eastern Europe were notable in that he communicated the current state of neurophysiology to scientists there. Ed had a major influence on the development of behavioral neurophysiology in Japan due to a six month visit there in 1969 helping to establish a neurophysiology laboratory in Kyoto and the stream of young Japanese physiologists that visited Bethesda over the years. He was the current chairman of the Neurobiology Section of the National Academy of Sciences, presiding over a record number of inductees into that section of the Academy. Ed was involved in the creation of the Society for Neuroscience and served as the Society's President in 1974-1975 and as an Editor of the Neural Systems Section of the Journal of Neuroscience from the inception of the journal. Other editorial contributions were as Chief Editor for the Journal of Neurophysiology from 1974-1977 and as a current member of the editorial board for Trends in Neuroscience, Experimental Brain Research and the Journal of Motor Behavior. An important contribution that Ed made to neuroscience that may be unrecognized was his participation on many review committees that ultimately awarded funds and prizes for neuroscience research; most prominent among these were duties for the McKnight Foundation and for the Albert Lasker Medical Research Awards. Ed's scientific contributions to research were acknowledged by several awards from the United States Department of Health and Human Services, by peer-elected memberships to the United States' National Academy of Sciences and the Institute of Medicine and by the cherished Karl S. Lashley Award of the American Philosophical Society.

Ed's death came as a great blow to all of us who knew him and especially to those who had worked with and learned much from him in the Laboratory of Neurophysiology. In a sense, the greatest part of Ed's career was yet to come since he not only would have continued to pursue new research goals, but perhaps more importantly Ed would have been a senior member of the neurobiology research community who could have provided direction and perspective to his past associates and to those who would have continued to flock to the Laboratory of Neurophysiology to learn all that was offered there. We will all miss Edward Vaughn Evarts.

Jerome N. Sanes

Section on Human Motor Control

Medical Neurology Branch

National Institute of Neurological and Communicative Disorders and Stroke Bethesda, Maryland 